\title{
In silico characterization of microsatellites in Eucalyptus spp.: Abundance, length variation and transposon associations
}

\author{
Edenilson Rabello, Adriane Nunes de Souza, Daniel Saito and Siu Mui Tsai \\ Universidade de São Paulo, Centro de Energia Nuclear na Agricultura, \\ Laboratório de Biologia Celular e Molecular, Piracicaba, SP, Brazil.
}

\begin{abstract}
This study assessed the abundance of microsatellites, or simple sequence repeats (SSR), in 19 Eucalyptus EST libraries from FORESTs, containing cDNA sequences from five species: E. grandis, E. globulus, E. saligna, E. urophylla and E. camaldulensis. Overall, a total of 11,534 SSRs and 8,447 SSR-containing sequences $(25.5 \%$ of total ESTs) were identified, with an average of $1 \mathrm{SSR} / 2.5 \mathrm{~kb}$ when considering all motifs and $1 \mathrm{SSR} / 3.1 \mathrm{~kb}$ when mononucleotides were not included. Dimeric repeats were the most abundant (41.03\%), followed by trimerics (36.11\%) and monomerics (19.59\%). The most frequent motifs were A/T (87.24\%) for monomerics, AG/CT (94.44\%) for dimerics, CCG/CGG (37.87\%) for trimerics, AAGG/CCTT (18.75\%) for tetramerics, AGAGG/CCTCT (14.04\%) for pentamerics and ACGGCG/CGCCGT (6.30\%) for hexamerics. According to sequence length, Class II or potentially variable markers were the most commonly found, followed by Class III. Two sequences presented high similarity to previously published Eucalyptus sequences from the NCBI database, EMBRA_72 and EMBRA_122. Local blastn search for transposons did not reveal the presence of any transposable elements with a cut-off value of $10^{-50}$. The large number of microsatellites identified will contribute to the refinement of marker-assisted mapping and to the discovery of novel markers for virtually all genes of economic interest.
\end{abstract}

Key words: Eucalyptus, EST, microsatellite, simple sequence repeat (SSR), molecular marker.

Accepted: May 28, 2004; Received: May 30, 2005.

\section{Introduction}

Trees represent the majority of terrestrial biomass production and the main resource for forestry and woodprocessing industries worldwide. Increases in wood productivity and quality have stimulated forest management research and technological advances in timber, pulp and paper, with little contribution from biotechnology. Forest genomics began when expressed sequence tag (EST) projects were initiated in pine (Allona et al. 1998) and poplar (Sterky et al. 1998), demonstrating the usefulness of EST sequencing, which was later proven to be a cheap and efficient method for finding genes (Bhalerao et al. 2003).

Eucalyptus is extensively grown in commercial forest plantations in Brazil, mostly established through vegetative propagation based on rooted cuttings (Campinhos and Ikemori 1980). The genetic mapping of species from this genus has been achieved by the use of a variety of marker types, including RAPD (Gan et al. 2003), RFLP (Byrne et al. 1995), AFLP (Marques et al. 1998), isozymes (Byrne et

Send correspondence to Siu Mui Tsai. Universidade de São Paulo, Centro de Energia Nuclear na Agricultura, Laboratório de Biologia Celular e Molecular, Av. Centenário 303, 13.416-000, Piracicaba SP, Brazil. Email: tsai@cena.usp.br. al. 1995) and microsatellites (Brondani et al. 2002). Also, some QTLs have been located on the genetic maps, which are generally involved in traits of economic interests: vegetative propagation ability (Grattapaglia et al. 1995); seedling height and leaf area (Byrne et al. 1997a); frost tolerance (Byrne et al. 1997b); growth and wood quality (Grattapaglia et al. 1996); and monoterpene composition (Sepherd et al. 1999).

Parental or individual clone identification by molecular methods has become increasingly important for genetic characterization of Eucalyptus spp. Under this new context, the method of choice must allow the design of consistent primer sets for clonal, as well as paternal and maternal identities. Historically, the use of hypervariable probes, designed as a variable number of tandem repeats (VNTRs, Nakamura et al. 1987) or minisatellites (Jeffreys et al. 1985), used simultaneously to detect multiple loci have represented an important step towards higher standards of reliability and reproducibility. Heterozygosities of some minisatellite loci can reach values as high as 0.99 (Jeffreys et al. 1988). However, it was soon realized that most of these hypervariable loci were clustered at proterminal regions (Royle et al. 1988) and thus less useful in genetic 
mapping for general purposes. Soon after these findings, a new class of polymorphic markers, named microsatellites (Litt and Luty 1989) or simple sequence repeats - SSRs (Tautz 1989) was described. This type of DNA polymorphism could be detected only after PCR amplification of DNA and separation on polyacrylamide gel electrophoresis. All simple sequence repeats with a repeat length of a few base pairs could be considered microsatellites ( $\mathrm{Wu}$ and Tanksley 1993). In recent years, the use of SSR markers has become the method of choice for applications in forestry industries, because it is a fast and simple technique when compared to AFLPs, RFLPs or isozymes.

Given the interest of the plant genetics community in SSRs as genetic markers, there has been a particular concern in the establishment of methods for rapid identification of robust and informative SSRs linked to genes of agronomic significance. Compared to genome-wide isolation approaches, gene-targeted strategies are more likely to yield SSRs that are relevant to the goals of marker-assisted selection and germplasm assessment. In the former approach, linkage disequilibrium between an SSR and a gene is fortuitous and frequently insufficient for transfer to other germplasm of interest (Cardle et al. 2000). For Eucalyptus fingerprinting, by using an inter-simple sequence repeat (ISSR) PCR-based enrichment technique for microsatellite-rich regions, primer sets were constructed to amplify mono, di, tri, hexa and nonanucleotide repeats, which were also able to amplify the corresponding microsatellite loci from five different Eucalyptus spp.: E. grandis, E. nitens, E. globulus, E. camaldulensis and E. urophylla (Van der Nest et al. 2000).

In the search for transposable elements (TEs), two major groups are expected - RNA mediated transposable elements or retroelements, and DNA transposable elements or classical transposons. They are mutagenic agents and their activity in the plant genome may provide high levels of variability, which may be used for genetic fingerprinting, to create novel genes and to modify genetic functions (Bennetzen 2000). Rossi et al. (2001) surveyed the TEs from the sugarcane expressed sequence tag (SUCEST) project containing 260,781 sequences and found 276 clones showing homology to previous reported TEs using a stringent cut-off value of $\mathrm{e}^{-50}$ or better. More recently, data obtained by Marques et al. (2002) and Kirst et al. (2005) demonstrated the feasibility of using SSRs for genetic analysis of several commercial Eucalyptus species.

This study assessed the abundance of SSRs in the Eucalyptus EST-based libraries, by using the recent submission of a large volume of cDNA sequences emerging from the Eucalyptus Genome Sequencing Project Consortium (FORESTs) which allowed the estimation of SSR frequency, repeat unit size and classification into three different groups: Class I $\geq 20 \mathrm{pb}$, Class II = between 11-20 pb, and Class III $\leq 11 \mathrm{pb}$. Using a local blastn algorithm
(BLAST 2.0 - http:/www.ncbi.nlm.nih.gov/blast), dispersed repetitive elements were surveyed at the flanking sites of the SSRs and their occurrence evaluated within the Eucalyptus EST libraries.

\section{Material and Methods}

\section{Sequence data sources}

Data were mined from FORESTs - Eucalyptus Genome Sequencing Project Consortium, supported by FAPESP (Fundação de Amparo à Pesquisa do Estado de São Paulo - Brazil) - which contains cDNA sequences from five species of Eucalyptus: E. grandis, E. globulus, E. saligna, E. urophylla and E. camaldulensis. Sequences were obtained from 19 libraries of different plant tissues at different growth stages, under various physiological and stressed conditions (frost, drought, attack of fungal pathogens and insects, boron and phosphorus deficiencies, light/ dark growth). In this study, 17,286 singleton and 15,794 consensus sequences, for a total of 33,080 non-redundant ESTs, were screened for microsatellites or simple sequence repeats (SSRs). Singletons containing more than $550 \mathrm{bp}$ were cut at their 3' end prior to SSR mining, in order to avoid analysis of low-quality bases.

\section{Mining FORESTs database for SSR identification}

Mono, di, tri, tetra, penta and hexanucleotide microsatellites were evaluated for their abundance and length distribution. Different SSR motifs were surveyed within the FORESTs database where complementary sequences were considered as belonging to the same class (e.g., AC, CA, TG, GT). The identified SSRs were categorized into three groups based on the length of the repeat units (Class I $\geq 20 \mathrm{bp}$, Class II = between 11-20 bp, and Class III $\leq 11$ bp) (Temnykh et al. 2001). Dispersed repetitive elements were surveyed at the flanking sites of the SSRs.

The query for SSR was supported by Perl script search module MISA (http://pgrc.ipk-gatersleben.de/misa), allowing the identification of perfect and compound microsatellites (Varshney et al. 2002). Perfect microsatellites were defined as sequences of ten or more mononucleotide repeats, six or more dinucleotide repeats, five or more tri, tetra, penta and hexanucleotide repeats. Compound microsatellites were considered as those present in the same EST and distant by a maximum of $100 \mathrm{bp} . \mathrm{A}_{n}$ repeats distant by a maximum of $50 \mathrm{bp}$ from the 3 ' end of sequences were not considered as microsatellites, as they may represent poly-A tails of eucaryotic mRNA. Since the cloning procedure was vector-oriented, there was no need to eliminate poly-T tails from our analyses.

Additional analysis was performed in order to investigate possible matches among the EST-derived SSR sequences identified herein to those from genomic databases. Seventy SSR markers from E. grandis and E. urophylla (Brondani et al. 2002, Brondani et al. 1998), 8 from $E$. 
sibieri (Glaubitz et al. 2001), 8 from E. nitens (Byrne et al. 1996, http://www.ffp.csiro.au/tigr/molecular/eucmsps. html), 26 from E. globulus (http:/www.ffp.csiro.au/tigr/ molecular/eucmsps.html) and 24 from the NCBI database (http://www.ncbi.nlm.nih.gov) were cross-matched against our results, with a local blastn algorithm.

\section{Searching for transposable elements associated to SSRS}

Initially, a possible association between Eucalyptus SSRs and dispersed repetitive elements was searched by BLAST analysis, where sequences flanking the SSR motifs were used as queries. Due to the strategy for the Eucalyptus genome construction (FORESTs), there was no need for setting simple Perl scripts for semiautomated identification of nonreduntant SSR loci (Temnykh et al. 2001). TIGR v.2 and REPBASE 8.9 public databases, which gather transposable elements (TEs) sequence data from diverse organisms, were utilized as blastn local databases. Only SSR-containing sequences were used as queries. Positive identification of transposable elements was performed with a maximum expectation value of $10^{-50}$ to avoid spurious matches (Rossi et al. 2001).

\section{Results}

Microsatellite frequency, distribution and transposon association

A total of 33,080 EST data representing 29,058,996 bp from the Eucalyptus Genome Sequencing Project Consortium (FORESTs) were mined for microsatellites. SSRs were analyzed for abundance, length variation, distribution and transposon associations. In all, 11,534 SSRs and 8,447 SSR-containing sequences $(25.5 \%$ of total ESTs) were identified, with an average of $1 \mathrm{SSR} / 2.5 \mathrm{~kb}$ (or $1 \mathrm{SSR} /$ $3.1 \mathrm{~kb}$ when mononucleotides were not considered) (Table 1). In cereals, including barley, maize, oat, rice, rye and wheat, lower frequencies of SSRs (7-10\% of total ESTs) were found from their available genome database (Varshney et al. 2002).

The most frequently found motifs were: $\mathrm{A} / \mathrm{T}$ (87.24\%) for monomerics, AG/CT (94.44\%) for dimerics, $\mathrm{CCG} / \mathrm{CGG}(37.87 \%)$ for trimerics, AAGG/CCTT

Table 1 - General statistics in the search for SSRs in Eucalyptus ESTs from the FORESTs Project (FAPESP-ONSA).

\begin{tabular}{lr}
\hline Total number of sequences analyzed & 33,080 \\
Total size of examined sequences (bp) & $29,058,996$ \\
Number of identified SSRs & 11,534 \\
Number of SSR-containing sequences & 8,447 \\
Number of sequences containing more than one SSR & 2,500 \\
Number of compound SSRs $^{1}$ & 1,823 \\
\hline
\end{tabular}

${ }^{1}$ In the same EST, less than 100 bp apart.
(18.75\%) for tetramerics, AGAGG/CCTCT (14.04\%) for pentamerics and ACGGCG/CGCCGT (6.30\%) for hexamerics (Figure 1). According to sequence length, Class II or potentially variable markers were the most common (42.36\%), followed by Class III (32.84\%) (Figure 2). Dimeric repeats were the most abundant (41.03\%), followed by trimerics (36.11\%) and monomerics (19.59\%). The SSRs contained virtually no pentanucleotide repeats $(0.49 \%)$ (Figure 3$)$. Figure 4 shows the number of SSRs according to the number of repeat units. The number of SSRs

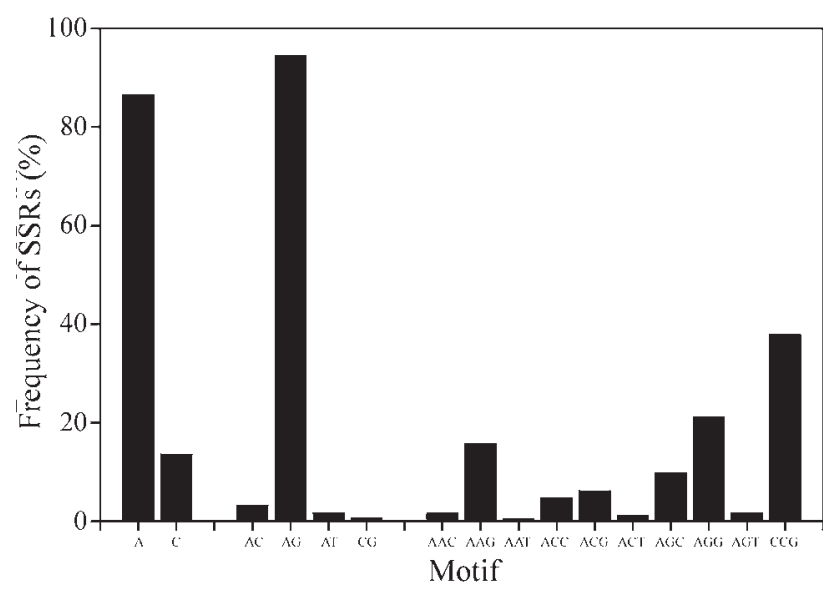

Figure 1 - Frequency of SSRs according to motifs, mined from the FORESTs database (11,534 SSRs).

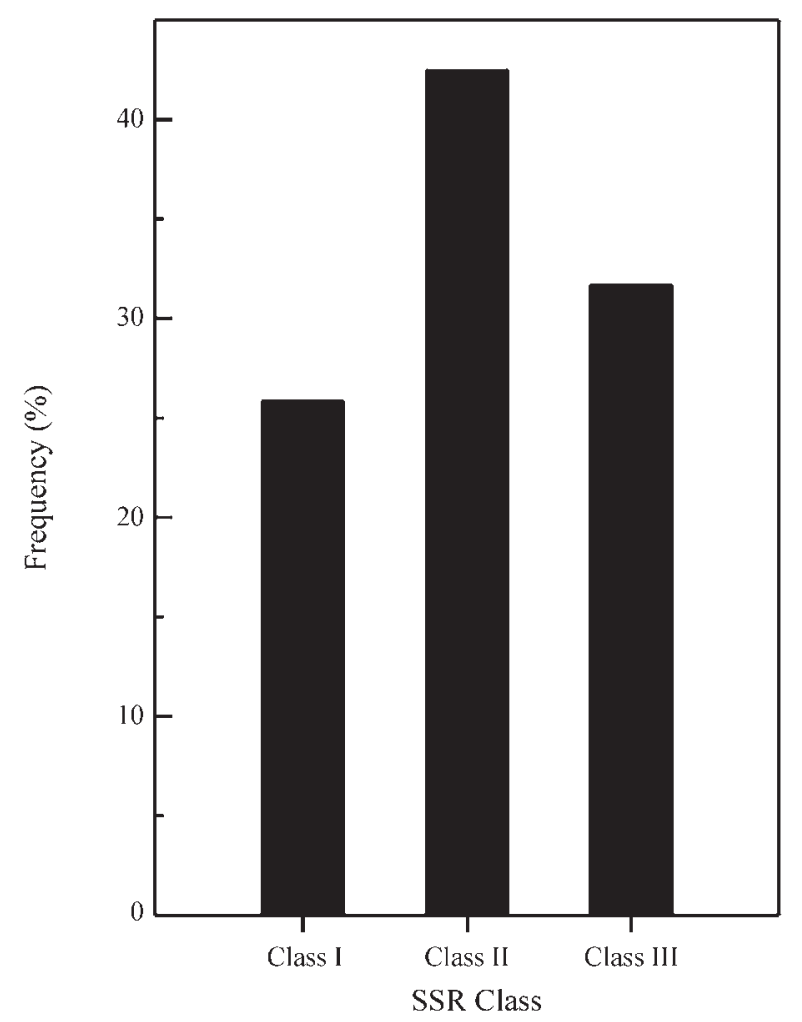

Figure 2 - Distribution of SSRs into classes in Eucalyptus spp. from the FORESTs database (11,534 SSRs). 


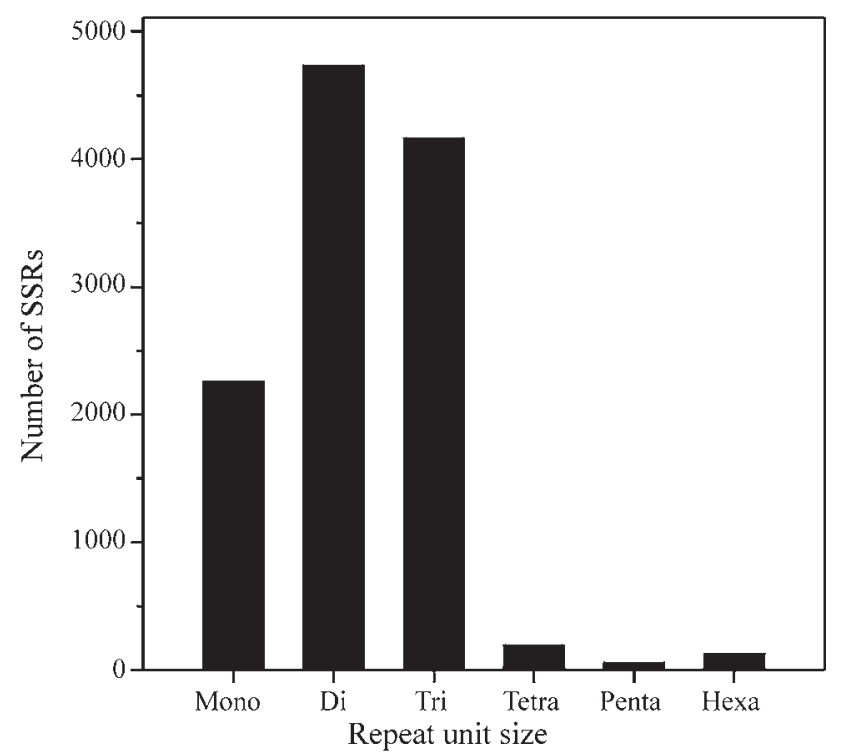

Figure 3 - Number of SSRs according to repeat unit size (motif length) in Eucalyptus spp. Di, tri and monomeric repeats are the most frequently found in the FORESTs database.

in each motif length decreases with the increase in number of repeat units, except for mono and dinucleotides.

The cross-matching analysis of the identified SSRs with the published genomic-derived Eucalyptus sequences retrieved only two highly similar hits: EMBRA_72 (Expect: $10^{-66}$, Identities: 97\%) and EMBRA_122 (Expect: $10^{-66}$, Identities: $88 \%$ ).

\section{Transposable elements associations}

Local BLAST search for transposons against TIGR v. 2 and REPBASE 8.9 did not reveal the presence of any transposable element with a cut-off value of $10^{-50}$. Only nine SSR-containing sequences were associated with $45 \mathrm{~S}$ rDNA-like sequences, with identities $\geq 91 \%$ and expect values $\leq 10^{-87}$ (Table 2).

\section{Discussion}

Over the last decade, the ubiquity of SSRs in eukaryotic genomes and their usefulness as genetic markers has been well established. Microsatellites are simple, tandemly repeated mono to hexanucleotide sequence motifs flanked by unique sequences. They are valuable as genetic markers because they are codominant, detect high levels of allelic diversity, and are easily and economically assayed by PCR. High levels of SSR informativeness have been demonstrated for a variety of plant species and have prompted the initiation of SSR discovery programs for most important crops. Nonetheless, researchers have encountered a number of limitations, such as lack of DNA sequences in the available databases, a perceived low abundance of SSRs (when compared to mammals) and dif-
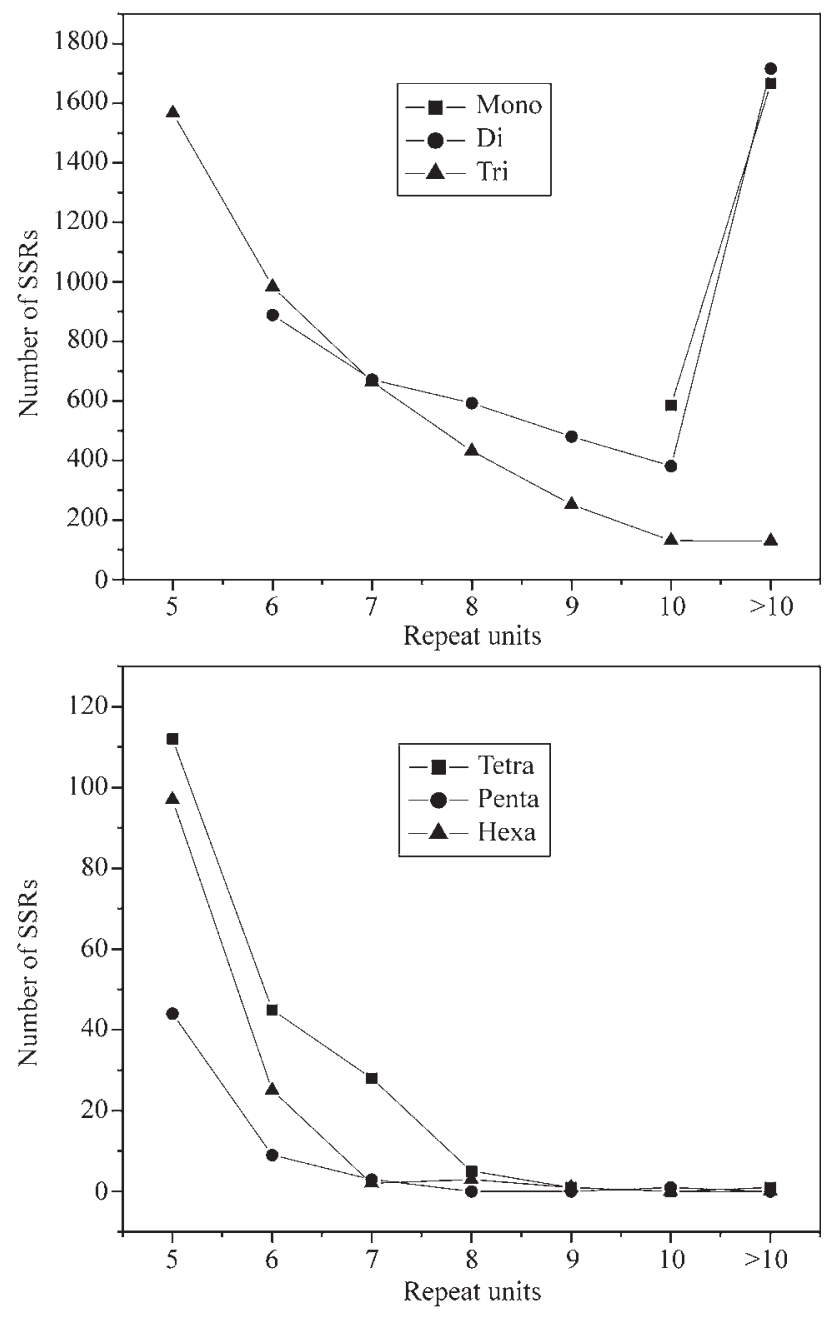

Figure 4 - Number of SSRs according to number of repeat units. The number of microsatellites in a particular repeat unit size decreases with the increasing number of repeat units, except for mono and dimerics.

Table 2 - Repetitive elements associated to microsatellites (SSR) determined in Eucalyptus ESTs from FORESTs.

\begin{tabular}{llcc}
\hline $\begin{array}{l}\text { SSR containing } \\
\text { sequences }\end{array}$ & Best hit & $\begin{array}{c}\text { Identities } \\
(\%)\end{array}$ & $\begin{array}{c}\text { Expect } \\
\text { value }\end{array}$ \\
\hline EGEQLV2201H05.g & $\begin{array}{l}\text { ORSgRGRR00000011 } \\
\text { 45S rDNA-like }\end{array}$ & 92 & 0.0 \\
EGUTRT3109D12.g & $\begin{array}{l}\text { ORSgRGRR00000011 } \\
\text { 45S rDNA-like }\end{array}$ & 92 & 0.0 \\
EGEQLV1201D10.g & $\begin{array}{l}\text { ORSgRGRR00000001 } \\
\text { 45S rDNA-like }\end{array}$ & 94 & e-123 \\
EGABST6055D11.g & $\begin{array}{l}\text { ORSgRGRR00000001 } \\
\text { 45S rDNA-like }\end{array}$ & 96 & e-136 \\
EGCBLV2219H11.g & $\begin{array}{l}\text { ORSgRGRR00000001 } \\
\text { 45S rDNA-like } \\
\text { ORSgRGRR00000001 }\end{array}$ & 98 & 0.0 \\
EGCBSL5005G05.g & $\begin{array}{l}\text { 45S rDNA-like } \\
\text { ORSgRGRR00000011 } \\
\text { 45S rDNA-like } \\
\text { EGCBSL4038C07.g }\end{array}$ & 91 & 0.0 \\
EGEZLV2203H01.g & $\begin{array}{l}\text { ORSgRGRR00000010 } \\
\text { 45S rDNA-like } \\
\text { ORSgRGRR00000001 } \\
\text { 45S rDNA-like }\end{array}$ & 96 & 0.0 \\
EGMCSL5073G06.g & 95 & 0.0 \\
\hline
\end{tabular}


ferences in the most common types of repeats found (Cardle et al. 2000).

Even though plant SSRs can be about 10 times less frequent than those found in humans, the screening of large numbers of clones and the development of selective SSR enrichment techniques have proven to be advantageous techniques for plant geneticists (Cardle et al. 2000). Results from screening a rice genomic library suggest that there are about 5,700-10,000 microsatellites, with the relative frequency of different repeats decreasing with increasing size of the motif (McCouch et al. 1997). Our data have shown a high number of SSRs - 11,534 out of a total of 33,080 FORESTs data representing 29,058,996 bp, as well as 8,447 SSR-containing sequences (25.5\% of total ESTs), with an average of $1 \mathrm{SSR} / 2.5 \mathrm{~kb}$ or $1 \mathrm{SSR} / 3.1 \mathrm{~kb}$ (excluding mononucleotides), which is about four times ( $1 \mathrm{SSR} / 14 \mathrm{~kb})$ that found for Arabidopsis (Cardle et al. 2000) and about twice (1 SSR/ $6.0 \mathrm{~kb}$ ) that found for cereals (Varshney et al. 2002).

Motif $\mathrm{A} / \mathrm{T}$ was found to be more abundant than $\mathrm{C} / \mathrm{G}$ in exons in all the taxa studied by Tóth et al. (2000), which is in agreement with our data. Moreover, the high percentage of the AG/CT motif is in accordance to a previous study conducted in SSR-enriched genome libraries from two $E u$ calyptus species - E. urophylla and E. grandis (Brondani et al. 1998) and in cereal species ESTs (Varshney et al. 2002). Among the trimerics, motif CCG/CGG was the most abundant, a result also obtained by Varshney et al. (2002). Moreover, $79.50 \%$ of trinucleotides were represented by GC-rich motifs (containing $\geq 2 \mathrm{G}$ and/or C), suggesting that they may be associated with genes (Temnyhk et al. 2001). Along with CCG/CGG trinucleotides, GGA/TTC, CCT/AGG, GAA/TTC and CCG/GGC can form hairpinlike structures, which may stabilize them and allow them to escape from repair mechanisms (Tóth et al. 2000, Li et al. 2002). They are, therefore, expected to be more frequent. In fact they represent $79.30 \%$ the SSRs found. As for tetra and hexanucleotide repeats, there was a noticeable proximity among the frequencies of the first and second most abundant motifs (data not shown). When repeat unit sizes were analyzed, dinucleotides were the most abundant, a result that agrees with Cardle et al. (2000) in a study on Arabdopsis, but differs from that of Varshney et al. (2002), who found trinucleotides as the most frequent in cereals, followed by dinucleotides.

It remains unknown why certain repeat motifs are more common than others, or the reason they vary so much among or even within taxa. For example, the fungi species $P$. chrysosporium and $U$. maydis have $\mathrm{A}_{n}$ frequencies of 35 and $70 \%$, respectively (Lim et al. 2004). Furthermore, SSR motifs, abundance, and mutation rates are different among species, with a wide range of genetic properties (Cruz et al. 2005).

The division of microsatellites into classes represents their potential as molecular markers. Class I repeats are highly polymorphic, class II are less variable, and class has a mutation potential similar to most unique sequences (Temnyhk et al. 2001). Class II represented $42.36 \%$ of all SSRs found and it is the most common within the repeat unit sizes in which it appears (mono to tetranucleotides). Although class I represented only about one fourth of all microssatellites, they should be the starting point for the design of molecular markers as they are the most polymorphic.

Two different patterns were observed when comparing the number of motif lengths to the number of repeat units. While there are well-defined decaying curves for tri to hexameric motifs, this tendency was not observed for mono and dimerics, which is in agreement with the results of Varshney et al. (2002).

Only two SSR sequences (EMBRA_72 and EMBRA_122) were identified by searching the available Eucalyptus genomic-derived SSR databases. This is probably due to the fact that microsatellites from these databases may be located in noncoding regions, or that these databases are still reduced.

In contrast to a similar study conducted in sugarcane (Rossi et al. 2001), we could not detect any relationships between the SSR-containing sequences and TEs at a cut off value of $10^{-50}$. This bias may be due to differences in the total number of ESTs analyzed, which was almost 10 times lower in the present investigation. Also, we used only SSR-containing sequences in our analysis, which may also have contributed to a lower SSR-TE correlation rate.

In a recent review based on computational and experimental characterization of physically clustered SSRs in plants, the type and frequency of SSRs in plant genomes were investigated using the expanding quantity of DNA sequence data deposited in public databases (Cardle et al. 2000). For example, 306 genomic DNA sequences longer than $10 \mathrm{~kb}$ and 36,199 EST sequences were searched in Arabidopsis for all possible mono- to pentanucleotide repeats, with an average of 1 SSR for every $6.04 \mathrm{~kb}$ in the genomic DNA, decreasing to one every $14 \mathrm{~kb}$ in ESTs. Similar frequencies were also found in other plant species, although higher SSR frequencies associated to Eucalyptus ESTs were observed in the present study, when compared to different cereal or naturally-occurring tree species. On the basis of these findings and the previous data from other authors, we can conclude that there is a good potential for using the present approach for the targeted isolation of single or multiple, physically clustered SSRs linked to any Eucalyptus gene that has been mapped using DNA-based markers. Further mining within the available databases will be needed if unique primer pairs for Eucalyptus spp. are requested for genetic discrimination.

\section{Acknowlegements}

Data from this work were mined from FOREST database, supported by FAPESP-ONSA. The group collabo- 
rated on the FOREST sequencing genome from AEG program - Agricultural and Environmental Genomes (Proc. 00/10168-6). We gratefully acknowledge CNPq/CAPES for fellowships granted to all authors of this study.

\section{References}

Allona I, Quinn M, Shoop E, Swope K, St. Cyr S, Carlis J, Riedl J, Retzel E, Campbell MM, Sederoff R and Whetten RW (1998) Analysis of xylem formation in pine by cDNA sequencing. Proc Natl Acad Sci USA 95:9693-9698.

Bhalerao R, Nilsson O and Sandberg G (2003) Out of the woods: Forest biotechnology enters the genomic era. Curr Opin Biotechnol 14:206-213.

Bennetzen JL (2000) Transposable element contributions to plant gene and genome evolution. Plant Mol Biol 42:251-69.

Brondani RPV, Brondani C and Grattapaglia D (2002) Towards a genus-wide reference linkage map for Eucalyptus based exclusively on highly informative microsatellite markers. Mol Genet Genomics 267:338-347.

Brondani RPV, Brondani C, Tarchini R and Grattapaglia D (1998) Development, characterization and mapping of microsattelite markers in Eucalyptus grandis and E. urophylla. Theor Appl Genet 97:816-827.

Byrne M, Marques-Garcia MI, Uren T, Smith DS and Moran GF (1996) Conservation and genetic diversity of microsatellite loci in the genus Eucalyptus. Aust J Bot 44:331-341.

Byrne M, Murrell JC, Allen B and Moran GF (1995) An integrated genetic linkage map for eucalyptus using RFLP, RAPD and isozyme markers. Theor Appl Genet 91:869-875.

Byrne M, Murrell JC, Owen JV, Kriedemann P, Williams ER and Moran GF (1997a) Identification and mode of action of quantitative trait loci affecting seedling height and leaf area in Eucalyptus nitens. Theor Appl Genet 94:674-681.

Byrne M, Murrell JC, Owen JV, Williams ER and Moran GF (1997b) Mapping of quantitative trait loci influencing frost tolerance in Eucalyptus nitens. Theor Appl Genet 95:975979 .

Campinhos E and Ikemori Y (1980) Mass production of Eucalyptus spp. by rooting cuttings. In: IUFRO Symp. Genet. Improvement and Productivity of Fast-Growing Trees, São Paulo, Brazil, pp 60-67.

Cardle L, Ramsay L and Milbourne D (2000) Computational and experimental characterization of physically clustered simple sequence repeats in plants. Genetics 156:847-854.

Cruz F, Pérez M and Presa P (2005) Distribution and abundance of microsatellites in the genome of bivalves. Gene 346:241247.

Gan S, Shi J, Li M, Wu K, Wu J and Bai J (2003) Moderatedensity molecular maps of Eucalyptus urophylla S.T. Blake and E. tereticornis Smith genomes based on RAPD markers. Genetica 118:59-67.

Glaubitz JC, Emebiri LC and Moran GF (2001) Dinucleotide microsatellites from Eucalyptus sieberi: Inheritance, diversity and improved scoring of single-base differences. Genome 44:1041-1045

Grattapaglia D, Bertolucci FLG, Penchel R and Sederoff RR (1996) Genetic mapping of quantitative trait loci controlling growth and wood quality traits in Eucalyptus grandis using a maternal half-sib family and RAPD markers. Genetics 144:1205-1214.
Grattapaglia D, Bertolucci FL and Sederoff RR (1995) Genetic mapping of QTLs controlling vegetative propagation in Eucalyptus grandis and E. urophylla using a pseudotestcross strategy and RAPD markers. Theor Appl Genet 90:933-947.

Jeffreys AJ, Royle NJ, Wilson V and Wong Z (1988) Spontaneous mutation rates to new length alleles at tandem-repetitive hypervariable loci in human DNA. Nature 332:278281.

Jeffreys AJ, Wilson V and Thein SL (1985) Hypervariable "minisatellite" regions in human DNA. Nature 314:67-73.

Kirst M, Cordeiro CM, Rezende GDSP and Grattapaglia D (2005) Power of microsatellite markers for fingerprinting and parentage analysis in Eucalyptus grandis breeding populations. J Hered 96:161-166.

Li Y-C, Korol AB, Fahima T, Beiles A and Nevo E (2002) Microsatellites: Genomic distribution, putative functions and mutational mechanisms: A review. Mol Ecol 11:24532465.

Lim S, Notley-McRobb L, Lim M and Carter DA (2004) A comparison of the nature and abundance of microsatellites in 14 fungal genomes. Fungal Genet Biol 41:1025-1036.

Litt M and Luty JA (1989) A hypervariable microsatellite revealed by in vitro amplification of a dinucleotide repeat within the cardiac muscle actin gene. Am J Hum Genet 44:397-401.

Marques CM, Araújo JA, Ferreira JG, Whetten R, O’Malley DM, LI B-H and Sederoff R (1998) AFLP genetic maps of Eucalyptus globulus and E. terticornis. Theoret Appl Genet 96:727-737.

Marques CM, Brondani RPV, Grattapaglia D and Sederoff R (2002) Conservation and synteny of SSR loci and QTLs for vegetative propagation in four Eucalyptus species. J Hered 105:474-478.

McCouch SR, Chen X, Panaud O, Temnykh S, Xu Y, Cho YG, Huang N, Ishii T and Blair M (1997) Microsatellite marker development, mapping and applications in rice genetics and breeding. Plant Mol Biol 35:89-99.

Nakamura Y, Leppert M, O'Connell P, Wolff R, Holm T, Culver M, Martin C, Fujimoto E, Hoff M and Kumlin E (1987) Variable number of tandem repeats (VNRT) markers for human genome mapping. Science 235:1616-1622.

Rossi M, Araujo PG and Van Sluys MA (2001) Survey of transposable elements in sugarcane expressed sequence tags (ESTs). Genet Mol Biol 24:147-154.

Royle NJ, Clarkson RE, Wong Z and Jeffreys AJ (1988) Clustering of hypervariable minisatellites in the proterminal regions of human autosomes. Genomics 3:352-360.

Sepherd M, Chaparro JX and Teasdale R (1999) Genetic mapping of monoterpene composition in an interspecific eucalypt hybrid. Theor Appl Genet 99:1207-1215.

Sterky F, Regan S, Karlsson J, Hertzberg M, Rohde A, Holmberg A, Amini B, Bhalerao R, Larsson M, Villarroel R, Van Montagu M, Sandberg G, Olsson O, Teeri TT, Boerjan W, Gustafsson P, Uhlen M, Sundberg B and Lundeberg J (1998) Gene discovery in the wood-forming tissues of poplar: Analysis of 5,692 expressed sequence tags. Proc Natl Acad Sci USA 95:13330-5.

Tautz D (1989) Hypervariability of simple sequences as a general source for polymorphic DNA markers. Nucl Acids Res 17:6463-6471 
Temnykh S, DeClerck G, Lukashova A, Lipovich L, Cartinhour S and McCouch S (2001) Computational and experimental analysis of microsatellites in rice (Oryza sativa L.): Frequency, length variation, transposon associations, and genetic marker potential. Genome Res 11:1441-1452.

Tóth G, Gáspari Z and Jurka J (2000) Microsatellites in different eukaryotic genomes: Survey and analysis. Genome Res 10:967-981.

Van der Nest MA, Steenkamp ET, Wingfield BD and Wingfield MJ (2000) Development of simple sequence repeat (SSR) markers in Eucalyptus from amplified inter-simple sequence repeats (ISSR). Pl Breeding 119:433-436.

Varshney RK, Thiel T, Stein N, Langridge P and Graner A (2002) In silico analysis on frequency and distribution of microsatellites in ESTs of some cereal species. Cell Mol Biol Lett 7:537-546

Wu K-S and Tanksley SD (1993) Abundance, polymorphism and genetic mapping of microsatellites in rice. Mol Gen Genet 241:225-235.

Associate Editor: Marie Anne Van Sluys 